Vol. 9 No. 1 April 2016

PSIBERNETIKA

\title{
TIPE KOMITMEN PERNIKAHAN PADA TIGA PASANG SUAMI ISTRI USIA REMAJA YANG HAMIL DI LUAR NIKAH
}

\author{
Rouwi Girlina Astri \\ Shanty Sudarji
}

\begin{abstract}
Early marriage by teenagers due to pregnancy before married have a high risk of divorce, because teenagers are not ready economically, physically and mentally yet in building family. But the risk of divorce can be avoided if there is a marriage commitment, because commitment related with better communication, greater happiness and constructive behavior when facing difficulties. Marriage commitment is a subjective experience where both husband and wife want to keep the marriage in bad and good times, feeling morally have to stay married, and forced to remain in marriage.

This research used a qualitative method with phenomenology approach, with interviews and observations method to collect data. This research conduct to three pairs of husband and wife with an age range of 16 to 22 years old who married because of pregnancy before married, with age of marriage minimum three years and maximum ten years. The result showed that three couple of subjects fulfilled personal type of marriage commitment, and at the same time, three of them also fulfilled moral type of marriage commitment. The households of three couple of subjects could be a living example that marriage could survive by having marriage commitment eventhough the marriage itself didn't start with the proper way as the culture and norm said. It could be the same way with the marriage which didn't cause by pregnancy before married, so that the divorce in Indonesia could be avoided.
\end{abstract}

Keywords : marriage commitment, teenagers, early marriage, pregnancy before married

\section{A. LATAR BELAKANG}

Remaja adalah masa peralihan dari masa kanak-kanak ke dewasa, meliputi semua perkembangan yang dialami sebagai persiapan memasuki masa dewasa (Gunarsa \& Gunarsa, 2012). Pada umumnya remaja memiliki rasa ingin tahu yang tinggi (high curiosity), sehingga cenderung ingin berpetualang menjelajah segala sesuatu dan mencoba hal yang belum pernah dialaminya. Hal ini menyebabkan remaja ingin mencoba melakukan apa yang sering dilakukan orang dewasa, termasuk yang berkaitan dengan masalah seksualitas (Azwar, dalam Azinar, 2013). Perubahan hormon dalam proses 
pertumbuhan fisik yang terjadi di masa remaja, juga menjadi salah satu faktor yang mendorong remaja melakukan hubungan seks (Rejeki dan Tinah, 2010).

Beberapa remaja perempuan mengaku bahwa mereka melakukan hubungan seksual pertama kali karena ingin menyenangkan pacarnya sebagai sebuah bentuk pelayanan dan kesetiaan (Djamilah dan Kartikawati, 2014). Lebih lanjut lagi menurut Djamilah dan Kartikawati (2014), perilaku seks beresiko lainnya adalah adanya anggapan bahwa kegiatan seks pra nikah dengan berganti-ganti pasangan pada remaja, khususnya remaja laki-laki, sebagai suatu kebanggaan dan ajang mempertontonkan maskulinitas di kalangan remaja seusia mereka. Menurut Sarwono (dalam Lubis, 2013), perilaku seks bebas adalah segala tingkah laku yang didorong oleh hasrat seksual, baik yang dilakukan dengan lawan jenis, maupun sesama jenis tanpa adanya ikatan pernikahan menurut agama. Sementara menurut Mu'tadin (dalam Lubis, 2013) perilaku seksual pranikah merupakan perilaku seksual yang dilakukan tanpa melalui proses pernikahan yang resmi menurut hukum maupun menurut agama dan kepercayaan masing-masing. Menurut Rejeki dan Tinah (2010) hubungan seksual pra nikah adalah perilaku seksual yang melibatkan sentuhan secara fisik antara pria dan wanita yang telah mencapai tahap hubungan intim yang dilakukan sebelum adanya ikatan yang sah berupa perkawinan.

Berdasarkan data yang diperoleh dari Survei Kesehatan Reproduksi Remaja Indonesia (SKRRI) pada tahun 2007, 1\% remaja wanita dan 6\% remaja pria di Indonesia mengaku pernah melakukan seks di luar nikah (Nugraheni \& Abdinnah, 2012). Dari Survei Demografi dan Kesehatan Indonesia (SDKI) tahun 2012, diketahui angka kehamilan remaja pada kelompok usia 15 - 19 tahun mencapai 48 dari 1000 kehamilan (Susanto, 2013). Bahkan, Badan Kependudukan dan Keluarga Berencana Nasional (BKKBN) tahun 2013 menemukan sebanyak 20,9\% remaja di Indonesia mengalami kehamilan dan melahirkan sebelum menikah (Isnaini, 2013). Berdasarkan penelitian dari Australian National University (ANU) dan Pusat Penelitian Kesehatan Universitas Indonesia (UI) tahun 2010/2011 di Jakarta, Tangerang dan Bekasi (Jatabek), dengan jumlah sampel 3006 responden usia 17-24 tahun, menunjukkan 20,9\% remaja mengalami kehamilan dan kelahiran sebelum menikah, serta 38,7\% remaja mengalami kehamilan sebelum menikah dan kelahiran setelah menikah (Aby \& Johara, 2012). Data statistik tersebut menjadi 
Vol. 9 No. 1 April 2016

PSIBERNETIKA

alasan yang mendasari penelitian difokuskan pada subyek yang bertempat tinggal di kota besar seperti Jakarta, Bekasi dan Tangerang.

Kehamilan remaja biasanya diikuti oleh terjadinya pernikahan dini. Angka kehamilan tidak diinginkan (KTD) selalu berbanding lurus dengan pernikahan dini, walaupun ini bukan satu-satunya penyebab pernikahan dini (Jalil, 2014). Penelitian yang dilakukan oleh Djamilah dan Kartikawati pada tahun 2014 memperoleh hasil bahwa dari delapan daerah penelitian, yaitu DKI Jakarta, Semarang, Banyuwangi, Lampung, Kabupaten Sukabumi, NTB, Kalimantan Selatan dan Sulawesi Utara, penyebab paling utama pernikahan dini adalah karena remaja tidak paham tentang kesehatan reproduksi. Para remaja mencobacoba melakukan aktivitas seksual di masa berpacaran dengan pasangannya (Djamilah \& Kartikawati, 2014). Aktivitas seksual tersebut dapat menimbulkan KTD yang menyebabkan terjadinya pernikahan dini.

Berdasarkan penelitian yang dilakukan di Jombang, pernikahan dini yang dilakukan oleh remaja, sebagian besar dilatarbelakangi oleh kehamilan di luar nikah, yaitu sebanyak 40\% atau 52 kasus (BPPKB Jombang, 2015). Sementara itu, pusat Studi Kriminologi Universitas Islam Indonesia di Yogyakarta menemukan 26,35\% dari 846 pasangan remaja yang menikah telah melakukan hubungan seksual pra nikah dimana 50\% nya menyebabkan kehamilan (Dhamayanti, 2013). Berdasarkan pantauan Dinas Kesehatan tahun 2006 di kabupaten Kulon Progo, sekitar 44\% calon pengantin remaja yang melakukan tes kehamilan, diketahui positif hamil (Dhamayanti, 2013). Sementara di DKI Jakarta, jumlah kehamilan tidak terencana terjadi pada pasangan yang menikah di usia muda, yaitu 16 sampai 20 tahun sebanyak 51,7\% (Djamilah \& Kartikawati, 2014).

Kehamilan yang terjadi di luar nikah tentunya mendapatkan reaksi dari masyarakat. Dampak sosial yang diterima remaja perempuan yang hamil di luar nikah antara lain dikucilkan, dicemooh, dikeluarkan dari sekolah, serta tekanan dari masyarakat yang mencela dan menolak keadaan tersebut (Sarwono, dalam Lubis, 2013). Hal ini diperkuat dengan hasil wawancara informal yang dilakukan oleh peneliti secara acak pada tiga orang dengan usia berbeda di Jakarta, pada bulan Mei 2015. Ketiga subyek mengutarakan pendapatnya sebagai masyarakat yang tidak mengalami kasus kehamilan di luar nikah, 
dengan catatan tambahan, dua dari tiga subyek yang diwawancara berstatus belum menikah.

Pendapat dari ketiga subyek mencerminkan fakta yang ada di masyarakat, bahwa beberapa remaja memilih untuk menikah sebagai jalan keluar terbaik dari kehamilan di luar nikah. Namun, pernikahan dini beresiko tinggi memungkinan terjadinya perceraian. Menurut Dariyo (dalam Ningrum, 2013), perceraian merupakan titik puncak dari pengumpulan berbagai permasalahan yang menumpuk beberapa waktu sebelumnya dan jalan terakhir yang harus ditempuh ketika hubungan pernikahan itu sudah tidak dapat dipertahankan lagi. Menurut Kierna (dalam Nurhajati \& Wardyaningrum, 2012), resiko perceraian sangat tinggi terjadi pada pasangan yang menikah di usia muda dibandingkan pada mereka yang menikah di usia matang. Hal ini didukung oleh Jalil (2014) yang menjelaskan bahwa pernikahan dini akan menyebabkan persoalan sosial seperti tingginya angka perceraian, karena remaja belum siap membangun keluarga oleh karena ketidaksiapan secara ekonomi, fisik dan mentalnya.

Menurut data Badan Urusan Peradilan Agama (Badilag), Mahkamah Agung (MA) mencatat selama periode 2005 hingga 2010 terjadi peningkatan perceraian hingga $70 \%$. Pada tahun 2010, terjadi 285.184 perceraian di seluruh Indonesia. Tiga penyebab terbesar pisahnya pasangan adalah akibat faktor ketidakharmonisan sebanyak 91.841 perkara, tidak ada tanggung jawab 78.407 perkara, dan masalah ekonomi 67.891 perkara (Putra, 2012).

Meskipun demikian, resiko perceraian seperti yang dijelaskan di atas tidak akan muncul jika ada komitmen dalam pernikahan. Menurut Adelina dan Andromeda (2014), pencegahan perceraian dapat dilakukan salah satunya dengan meningkatkan komitmen pernikahan. Komitmen dalam pernikahan merupakan salah satu aspek yang penting untuk mencapai keberhasilan pernikahan (Robinson \& Blanton dalam Adelina \& Andromeda, 2014). Menurut Wright (2000), yang membuat pernikahan bertahan adalah komitmen. Sama halnya seperti yang dijelaskan Segrin dan Flora (2011), bahwa secara umum pernikahan yang sukses salah satunya ditandai oleh komitmen pernikahan. Komitmen pernikahan adalah pengalaman subyektif dimana suami dan istri ingin tetap mempertahankan pernikahan baik dalam masa sulit maupun masa senang, merasa secara moral harus bertahan, dan keterpaksaan untuk tetap berada dalam pernikahan. Komitmen 
Vol. 9 No. 1 April 2016

PSIBERNETIKA

pernikahan ini terdiri dari tiga tipe, yaitu komitmen personal, moral dan struktural (Johnson, dalam Rahmatika \& Handayani, 2012). Komitmen dikatakan sebagai prediktor yang kuat dalam keutuhan pernikahan karena Stanley (dalam Lambert \& Dollahite, 2008), menjelaskan bahwa komitmen berhubungan dengan komunikasi yang lebih baik, kebahagiaan yang lebih besar dan tingkah laku yang konstruktif ketika sedang menghadapi kesulitan.

Seperti yang telah dijelaskan sebelumnya, pernikahan dini beresiko tinggi memungkinkan terjadinya perceraian. Namun, ada beberapa pernikahan dini yang disebabkan oleh kehamilan di luar nikah yang masih bertahan setelah bertahun-tahun lamanya karena adanya komitmen pernikahan. Hal ini dikarenakan komitmen adalah keputusan besar yang dibuat secara kognitif untuk terikat dalam sebuah hubungan dan memelihara hubungan tersebut seiring berjalannya waktu (Engel, dalam DeGenova, Stinnet, \& Stinnet, 2011). Menurut Djamilah dan Kartikawati (2014), pernikahan dini memiliki dampak ekonomi, sosial, kesehatan dan psikologis yang beresiko mengakibatkan perceraian. Namun komitmen dapat meminimalisasi resiko tersebut, karena komitmen tidak hanya sekedar menerima dan mentoleransi sikap negatif pasangan dalam hubungan, komitmen berarti bekerja demi perubahan dan tetap bersama seseorang tanpa memandang situasi yang tengah dihadapi (Wright, 2000).

\section{B. TUJUAN PENELITIAN}

Tujuan dari penelitian ini adalah untuk mengetahui tipe komitmen pernikahan pada tiga pasang suami istri usia remaja yang hamil di luar nikah.

\section{TINJAUAN TEORI}

\section{Definisi Komitmen Pernikahan}

Komitmen pernikahan atau perkawinan adalah pengalaman subyektif dimana suami dan istri ingin tetap mempertahankan perkawinan baik dalam masa sulit maupun masa senang, merasa secara moral harus bertahan, dan keterpaksaan untuk tetap berada dalam perkawinan (Johnson, dalam Rahmatika \& Handayani, 2012). Menurut Engel (dalam DeGenova, Stinnett, \& Stinnett, 2011) komitmen adalah keputusan besar yang dibuat secara kognitif untuk terikat dalam sebuah hubungan dan memelihara hubungan tersebut 
seiring berjalannya waktu. Sementara menurut Sternberg (dalam DeGenova et al., 2011), komitmen adalah ketika seseorang memilih untuk tetap bersama sesuatu atau seseorang dan bertahan hingga tujuan dari dibangunnya komitmen tersebut tercapai.

\section{Tipe Komitmen Pernikahan}

Komitmen pernikahan terdiri dari beberapa tipe. Dalam jurnalnya, Johnson et al. (1999) membagi komitmen menjadi tiga tipe yang dapat diukur secara terpisah, yaitu :

1. Komitmen personal, yang mengacu kepada keinginan individu untuk tetap bertahan di dalam hubungan dipengaruhi oleh :

a. individu ingin melanjutkan hubungan karena ada daya tarik pada pasangannya, baik dari segi fisik, karakter dan lain-lain yang ada dalam diri pasangan.

b. merasa ada daya tarik dengan hubungan itu sendiri, misalnya dari kegiatan yang dilakukan pasangan secara bersama-sama, dan

c. identitas pasangan, partisipasi individu dalam hubungan yang istimewa dapat menjadi aspek penting dalam konsep diri individu tersebut.

2. Komitmen moral, yang melibatkan rasa bertanggung jawab secara moral atau keharusan untuk tetap tinggal di dalam hubungan, juga terdiri dari tiga komponen yaitu :

a. kewajiban untuk mempertahankan hubungan mengacu pada nilai-nilai tentang moralitas, merasa bahwa sebuah pernikahan sebagai sesuatu yang berlangsung seumur hidup "sampai kematian memisahkan",

b. merasa bertanggung jawab secara pribadi kepada orang lain, merasa tidak adil jika meninggalkan pasangannya, karena pasangannya membutuhkan dirinya dan ia merasa telah berjanji untuk sehidup semati dengan pasangannya tersebut, dan

c. individu merasa berkewajiban untuk melanjutkan hubungan karena ia memiliki nilai konsistensi secara umum, ia berusaha mempertahankan apa yang telah dimulainya dari waktu ke waktu, termasuk pernikahan. 
Vol. 9 No. 1 April 2016

PSIBERNETIKA

3. Komitmen struktural, yang merupakan keterpaksaan untuk tetap tinggal di dalam hubungan, terdiri dari komponen :

a. ketergantungan pada hubungan dikarenakan alternatif lingkungan yang individu percaya akan tersedia jika hubungan berakhir. Contohnya, tersedianya kehidupan ekonomi yang layak, tempat tinggal, pekerjaan, dan kontak dengan anak,

b. tekanan sosial dari keluarga, teman, dan masyarakat sebagai reaksi tidak setuju jika terjadi perceraian,

c. proses birokrasi dan prosedur hukum perceraian yang sulit, menghabiskan waktu serta biaya, lalu

d. banyaknya investasi waktu dan sumber daya lain yang telah diberikan selama hubungan berlangsung dan tidak dapat diambil kembali, sehingga individu tidak ingin mengakhiri hubungan meskipun hubungan tersebut tidak memuaskan, karena hal ini berarti investasi yang telah diberikan selama ini sia-sia.

\section{METODE PENELITIAN}

Penelitian ini menggunakan metode kualitatif dengan pendekatan fenomenologi, karena peneliti ingin menggali suatu permasalahan secara mendalam untuk kasus yang spesifik. Perspektif fenomenologi menurut Husrell (dalam Moleong, 2014) adalah pendekatan untuk memperoleh pengetahuan tentang sesuatu (obyek) sebagaimana tampilnya dan menjadi pengalaman kesadaran manusia. Penelitian fenomenologi digunakan untuk mengungkap pengalaman manusia melalui deskripsi dari orang yang menjadi partisipan penelitian, sehingga peneliti dapat memahami pengalaman hidup partisipan.

Kriteria subyek yang digunakan dalam penelitian ini adalah (1) pasangan suami istri, (2) berusia 16 sampai 22 tahun, (3) pernikahan disebabkan oleh kehamilan di luar nikah, dan (4) usia pernikahan minimal tiga tahun dan maksimal sepuluh tahun. Usia pernikahan disyaratkan minimal tiga tahun karena puncak terjadinya perceraian dalam keluarga adalah pada tahun ketiga, dimana penyebab terbesarnya adalah pernikahan yang dilatarbelakangi oleh kehamilan di luar nikah (Hurlock, 2003). Selain itu, disyaratkan maksimal sepuluh 
tahun karena menurut Papalia et al. (2009) kebanyakan perceraian muncul selama masa sepuluh tahun pertama pernikahan.

Jumlah subyek dalam penelitian ini berjumlah 6 orang yang terdiri dari 3 pasang suami istri, dengan memenuhi kriteria yang ditentukan. Menurut Sarantakos (dalam Poerwandari, 2011) penelitian kualitatif diarahkan tidak pada jumlah sampel yang besar, melainkan pada kasus-kasus tipikal sesuai kekhususan masalah penelitian. Sementara Banister (dalam Poerwandari, 2011) menjelaskan bahwa penelitian kualitatif cenderung dilakukan dengan jumlah kasus sedikit. Suatu kasus tunggal pun dapat dipakai, bila dari kasus tunggal tersebut dapat diungkap informasi yang sangat mendalam.

Teknik pengumpulan data yang digunakan peneliti adalah observasi dan wawancara dengan pedoman umum (Poerwandari, 2011). Sementara teknik analisis yang digunakan dalam penelitian ini adalah analisis konten. Analisis konten dilakukan berdasarkan deskripsi melalui fenomena, kajian terhadap tema yang muncul, sampai interpretasinya (Poerwandari, 2011).

\section{E. HASIL}

Berdasarkan perbandingan hasil analisa komitmen pernikahan intersubyek, dapat disimpulkan bahwa ketiga pasang subyek memenuhi komitmen pernikahan tipe komitmen personal. Hal ini disebabkan karena adanya ketertarikan subyek pada pasangan, adanya ketertarikan pada hubungan dan subyek merasa identitasnya sebagai pasangan penting dalam hubungan yang sedang dijalani. Ketiga komponen tersebut membuat ketiga pasang subyek merasa ingin mempertahankan hubungan pernikahannya.

Pada saat bersamaan, tiga dari enam subyek juga memenuhi komitmen pernikahan tipe komitmen moral, yaitu subyek C, D dan E. Ini terjadi karena adanya rasa kewajiban untuk mempertahankan hubungan, rasa bertanggung jawab untuk tidak meninggalkan pasangan dan rasa kewajiban untuk melanjutkan apa yang telah dimulai. Terpenuhinya ketiga komponen tersebut membuat subyek C, D dan E merasa harus mempertahankan hubungan pernikahannya.

Ketiga pasang subyek tidak memenuhi komitmen struktrural. Subyek A, B dan F hanya memenuhi satu komponen, yaitu merasa telah banyak memberikan investasi waktu dan sumber daya lain dalam hubungan. Subyek $C$ hanya memenuhi satu komponen, yaitu 
Vol. 9 No. 1 April 2016

PSIBERNETIKA

ketergantungan pada hubungan. Subyek E hanya memenuhi satu komponen, yaitu merasa prosedur perceraian di Indonesia sulit. Sementara subyek D tidak memenuhi satu pun komponen dari komitmen struktural. Tidak terpenuhinya komitmen struktural yang dimiliki ketiga pasang subyek menyebabkan mereka tidak merasa terpaksa dalam mempertahankan hubungan pernikahannya.

Tabel Batasan Komitmen Pernikahan Inter Subyek

\begin{tabular}{|c|c|c|c|c|c|c|c|c|}
\hline \multirow[t]{2}{*}{ Tipe } & \multirow[t]{2}{*}{ Komponen } & \multicolumn{6}{|c|}{ Subyek } & \multirow[t]{2}{*}{ Kesimpulan } \\
\hline & & $\mathbf{A}$ & B & $\mathbf{C}$ & D & $\mathbf{E}$ & $\mathbf{F}$ & \\
\hline \multirow[t]{3}{*}{ Personal } & $\begin{array}{l}\text { Daya tarik } \\
\text { pada } \\
\text { pasangan }\end{array}$ & $\checkmark$ & $\checkmark$ & $\checkmark$ & $\checkmark$ & $\checkmark$ & $\checkmark$ & \multirow{3}{*}{$\begin{array}{l}\text { Ketiga pasang } \\
\text { subyek } \\
\text { memenuhi } \\
\text { ketiga } \\
\text { komponen tipe } \\
\text { komitmen } \\
\text { personal. }\end{array}$} \\
\hline & $\begin{array}{l}\text { Daya tarik } \\
\text { pada } \\
\text { hubungan }\end{array}$ & $\checkmark$ & $\checkmark$ & $\checkmark$ & $\checkmark$ & $\checkmark$ & $\checkmark$ & \\
\hline & $\begin{array}{l}\text { Identitas } \\
\text { pasangan }\end{array}$ & $\sqrt{ }$ & $\checkmark$ & $\checkmark$ & $\checkmark$ & $\checkmark$ & $\checkmark$ & \\
\hline \multirow[t]{3}{*}{ Moral } & $\begin{array}{l}\text { Kewajiban } \\
\text { pada } \\
\text { hubungan }\end{array}$ & $\sqrt{ }$ & $\checkmark$ & $\checkmark$ & $\checkmark$ & $\checkmark$ & - & \multirow{3}{*}{$\begin{array}{l}\text { Subyek C, D } \\
\text { dan E } \\
\text { memenuhi } \\
\text { ketiga } \\
\text { komponen tipe } \\
\text { komitmen } \\
\text { moral. }\end{array}$} \\
\hline & $\begin{array}{l}\text { Kewajiban } \\
\text { moral } \\
\text { pribadi }\end{array}$ & - & - & $\checkmark$ & $\checkmark$ & $\checkmark$ & $\checkmark$ & \\
\hline & $\begin{array}{l}\text { Nilai } \\
\text { konsistensi }\end{array}$ & $\sqrt{ }$ & $\checkmark$ & $\checkmark$ & $\checkmark$ & $\checkmark$ & $\checkmark$ & \\
\hline \multirow[t]{4}{*}{ Struktural } & Alternatif & - & - & $\checkmark$ & - & - & - & \multirow{4}{*}{$\begin{array}{l}\text { Tidak ada } \\
\text { subyek yang } \\
\text { memenuhi } \\
\text { keempat } \\
\text { komponen tipe } \\
\text { komitmen } \\
\text { struktural. }\end{array}$} \\
\hline & $\begin{array}{l}\text { Tekanan } \\
\text { sosial }\end{array}$ & - & - & - & - & - & - & \\
\hline & $\begin{array}{l}\text { Prosedur } \\
\text { terminasi }\end{array}$ & - & - & - & - & $\checkmark$ & - & \\
\hline & Investasi & $\checkmark$ & $\checkmark$ & - & - & - & $\checkmark$ & \\
\hline
\end{tabular}

\section{Keterangan :}

$\checkmark=$ Terpenuhi

- $\quad$ = Tidak terpenuhi 


\section{F. PEMBAHASAN}

Ketiga pasang subyek memenuhi komitmen personal sebab mereka menyayangi dan membutuhkan pasangannya sejak masih berpacaran, hal ini sejalan dengan pendapat Johnson (1999) mengenai komitmen personal, yang mengacu kepada keinginan individu untuk tetap bertahan di dalam hubungan. Subyek A dan B berpacaran selama dua tahun sebelum akhirnya menikah, subyek $\mathrm{C}$ dan $\mathrm{D}$ juga menjalin hubungan selama dua tahun sebelum menikah, sementara subyek E dan F berpacaran selama empat tahun sebelum mereka menikah. Dalam kurun waktu tersebut, mereka menjalani hubungan dengan serius untuk menikah di masa depan. Rasa saling menyayangi dan membutuhkan adalah alasan yang mendorong subyek B, D dan F bersedia untuk bertanggung jawab dan menikahi pasangannya yang hamil di luar nikah. Meskipun ketiga pasang subyek merasakan dampak ekonomi dari pernikahan dini yang mereka jalani, namun mereka masih tetap bersama hingga saat ini, karena masih adanya rasa saling menyayangi dan membutuhkan tersebut. Perasaan saling menyayangi dan membutuhkan tersebut tetap ada hingga kini, karena ketiga pasang subyek masih sering menghabiskan waktu bersama. Entah untuk berjalan-jalan keluar atau hanya mengobrol di rumah selepas kerja. Di samping itu, ketiga pasang subyek merasa bahwa peran mereka di dalam keluarga termasuk penting. Mereka merasa peran mereka dibutuhkan oleh keluarga, sehingga mereka ingin terus mempertahankan hubungan yang ada.

Subyek C, D dan E memenuhi komitmen moral dibandingkan ketiga subyek lainnya karena mereka merasa harus untuk tetap tinggal di dalam hubungan, hal ini sesuai dengan pendapat Johnson (1999) pada komitmen moral. Subyek C berasal dari keluarga dengan latar belakang keyakinan agama yang kuat, hal ini membuatnya tumbuh menjadi pribadi yang berpegang teguh pada ajaran agama, sehingga berpengaruh juga pada sikap C terhadap pernikahannya sendiri. Ia berpendapat bahwa janji pernikahan harus dipertahankan sampai kapanpun. Pendapatnya tersebut membuatnya merasa harus mempertahankan pernikahannya dengan D, apapun yang terjadi diantara mereka. Sama halnya dengan C, D juga berasal dari keluarga yang religius. Sedari kecil ia dididik untuk setia pada satu pasangan sampai maut memisahkan. Kesamaan prinsip tersebut membuat $\mathrm{C}$ dan $\mathrm{D}$ menjalani bahtera rumah tangga dengan dasar yang sama. Mereka berdua merasa bahwa mempertahankan hubungan pernikahan adalah suatu keharusan. Sementara itu, subyek E merasa anak-anaknya membutuhkan sosok ayah di masa tumbuh kembang mereka, sehingga menurutnya, mempertahankan pernikahan yang harmonis adalah sebuah 
keharusan. Ia bahkan rela bertahan dalam hubungan yang berada di ambang perpisahan karena alasan tersebut. Ketiga subyek lainnya yaitu A, B dan F tidak memenuhi komitmen moral karena A dan B melihat adanya kemungkinan untuk berpisah seandainya ada permasalahan yang tidak bisa diselesaikan dalam rumah tangga mereka. Sementara subyek F menyetujui adanya perceraian jika memang bercerai adalah keputusan terbaik bagi kedua belah pihak.

Ketiga pasang subyek tidak memenuhi komitmen struktural, karena tidak ada hal yang membuat mereka terpaksa untuk bertahan di dalam hubungan pernikahan (Johnson, 1999). Mereka semua menjalani pernikahannya karena keinginan pribadi tanpa tekanan dari pihak manapun. Subyek A, B dan F merasa bahwa investasi yang telah mereka berikan di dalam hubungan tergolong besar, sehingga mereka bisa saja terpaksa berada di dalam hubungan karena tidak ingin usaha yang telah mereka berikan sia-sia. Subyek C tidak bisa dan tidak mau membayangkan perpisahan dengan $\mathrm{B}$, sehingga ia bisa saja memiliki ketergantungan terhadap hubungannya. Subyek E merasa bahwa proses perceraian di Indonesia tergolong sulit, sehingga ia memilih tetap bertahan di dalam pernikahannya seandainya ia dan $\mathrm{F}$ harus bercerai. Namun kelima subyek tersebut nyatanya tidak memenuhi komponen lain di komitmen struktural. Sementara subyek D tidak memenuhi satu pun komponen komitmen struktural.

\section{G. SIMPULAN}

Berdasarkan hasil penelitian yang telah dilakukan, dapat disimpulkan bahwa ketiga pasang subyek memenuhi komitmen personal dalam pernikahannya. Di saat yang bersamaan, tiga dari enam subyek juga memenuhi komitmen moral dalam pernikahannya, yaitu subyek C, D dan E.

\section{H. SARAN}

Bagi peneliti selanjutnya, agar dapat lebih menggali penerimaan orang tua subyek dalam menyikapi kehamilan di luar nikah yang terjadi pada anak-anak mereka. Penerimaan orang tua bisa jadi berpengaruh terhadap komitmen pernikahan, namun hal ini perlu diteliti lagi.

Bagi ketiga pasang subyek dalam penelitian ini, agar konsisten untuk terus melakukan apa yang telah dilakukan selama ini untuk mempertahankan pernikahan. Bagi masyarakat, 
kehidupan rumah tangga ketiga pasang subyek dapat dijadikan sebagai contoh nyata bahwa hubungan pernikahan dapat dipertahankan dengan adanya komitmen pernikahan. Hal ini bisa berlaku juga untuk pernikahan yang tidak disebabkan oleh kehamilan di luar nikah, agar angka perceraian di Indonesia dapat ditekan jumlahnya.

Bagi pasangan suami istri usia remaja lain yang hamil di luar nikah, agar dapat mengambil contoh dari ketiga pasang subyek di penelitian ini dalam mengelola konflik di rumah tangga. Pasangan suami istri lainnya yang hamil di luar nikah juga dapat mengambil contoh dari ketiga pasang subyek untuk menjalankan peran sebagai suami/istri dengan sebaik mungkin, meluangkan waktu bersama, serta setia dan jujur pada pasangan, karena hal-hal kecil yang terkadang dianggap remeh tersebut ternyata memiliki peran besar dalam mempertahankan hubungan pernikahan.

\section{DAFTAR PUSTAKA}

Al-Mighwar, M. (2006). Psikologi Remaja. Bandung : Pustaka Setia.

DeGenova. M.K., Stinnet, N., \& Stinnett, N. (2011). Intimate Relationships, Marriages \& Families. New York : McGraw Hill.

Djamilah \& Kartikawati, R. (2014). Dampak Perkawinan Anak di Indonesia. Jurnal Studi Pemuda, Vol 3(1), 5-15.

Gunarsa, Y. S. D. \& Gunarsa, S.D. (2012). Psikologi Remaja. Jakarta : BPK Gunung Mulia.

Hurlock, E.B. (2003). Psikologi Perkembangan : Suatu Pendekatan Sepanjang Rentang Kehidupan. Jakarta : Erlangga.

Jalil, A. (2014). Fenomena Seksualitas Anak Muda (Studi Kasus tentang Dispensasi Kawin pada Pos Bantuan Hukum Pengadilan Agama di Sleman, Yogyakarta). Jurnal Studi Pemuda, Vol 3(1), 53.

Jordan, P.L., Stanley, S.M., \& Markman, H.J. (1999). Becoming Parents : How to Strengthen Your Marriage as Your Family Grows. California : Jossey-Bass.

Lauer, R.H., \& Lauer, J.C. (2012). Marriage and Family : The Quest for Intimacy. New York : McGraw-Hill.

Lubis, N.L. (2013). Psikologi Kespro : Wanita dan Perkembangan Reproduksinya. Jakarta : Kencana. 
Vol. 9 No. 1 April 2016

PSIBERNETIKA

Moleong, L.J. (2014). Metode Penelitian Kualitatif. Bandung : Remaja Rosdakarya.

Papalia, D.E., Olds, S.W., \& Feldman, R.D. (2009). HumanDevelopment : Perkembangan Manusia. Jakarta : Salemba Humanika.

Poerwandari, K. (2011). Pendekatan Kualitatif Untuk Penelitian Perilaku Manusia. Depok : LPSP3 Fakultas Psikologi Universitas Indonesia.

Sarwono, S.W. (2010). Psikologi Remaja. Jakarta : Raja Grafindo Persada.

Segrin, C. \& Flora, J. (2011). Family Communication. New York : Routledge.

Wright, H.N. (2000). Communication Key To Your Marriage : A Practical Guide to Creating a Happy, Fulfilling Relationship. California : Regal Books.

\section{Sumber internet :}

Aby \& Johara. (2012). 20,9 Persen ABG Hamil di Luar Nikah. Diakses pada 31 Maret 2016 dari poskotanews.com/2012/05/27/209-persen-abg-hamil-di-luar-nikah/

Adelina, R.A.A. \& Andromeda. (2014). Pasangan Dual Karir : Hubungan Kualitas Komunikasi dan Komitmen Perkawinan di Semarang. [Versi Elektronik]. JurnalDevelopmental and Clinical Psychology, Vol 3(1), 52.

Azinar, M. (2013). Perilaku Seksual Pranikah Beresiko Terhadap Kehamilan Tidak Diinginkan. [Versi Elektronik]. Jurnal Kesehatan Masyarakat, Vol 8(2), 153-160.

BPPKB Jombang. (2015). Edisi 1 Realita Pernikahan Usia Muda di Jombang. Diakses pada 23 April 2015 dari bppkb.jombangkab.go.id/realita-pernikahan-usia-muda-dikab-jombang/

Dhamayanti, M. (2013). Seputar Kesehatan Anak : Overview Adolescent Health Problems and Services. Diakses pada 23 April 2015 dari idai.or.id/public-articles/seputarkesehatan-anak/overview-adolescent-health-problems-and-services.html

Isnaini. (2013). 20,9\% Remaja Indonesia Hamil di Luar Nikah. Diakses pada 6 Februari 2015 dari okezone.com/read/2013/remaja-indonesia-hamil-di-luar-nikah

Johnson, M.P., Caughlin, J.P. \& Huston, T.L. (1999). The Tripartite Nature of Marital Commitment: Personal, Moral, and Structural Reasons to Stay Married. [Versi Elektronik]. Journal of Marriage and the Family, Vol 61, 160-162.

Lambert, N.M., \& Dollahite, D.C. (2008). The Threefold Cord : Marital Commitment in Religious Couple. [Versi Elektronik]. Journal of FamilyIssues, Vol 29(5), 593. 
Ningrum, P.R. (2013). Perceraian Orang Tua dan Penyesuaian Diri Remaja. [Versi Elektronik]. eJournal Psikologi, Vol 1(1), 74.

Nugrahaeni, M., \& Abdinnah, F. (2012). Studi : 20\% Remaja Jakarta Hamil di Luar Nikah. Diakses pada 6 Februari 2015 dari viva.co.id/news/read/344/studi-20\%remaja-jakarta-hamil-di-luar-nikah

Nurhajati, L. \& Wardyaningrum, D. (2012). Komunikasi Keluarga dalam Pengambilan Keputusan Perkawinan di Usia Remaja. [Versi Elektronik]. Jurnal Al-Azhar Indonesia Seri Pranata Sosial, Vol 1(4), 238.

Putra, E.P. (2012). Angka Perceraian Pasangan Indonesia Naik Drastis 70 Persen. Diakses 31 Maret 2015 dari republika.co.id/berita/nasional/umum/12/01/24/lya2ygangka-perceraian-pasangan-indonesia-naik-drastis-70-persen

Rahmatika, N.S., \& Handayani, M.M. (2012). Hubungan Antara Bentuk Strategi Coping Dengan Komitmen Perkawinan Pada Pasangan Dewasa Madya Dual Karir. [Versi Elektronik]. Jurnal Psikologi Pendidikan danPerkembangan, Vol 1(3), 3.

Rejeki, S., \& Tinah (2010). Hubungan Pengetahuan dan Sikap Remaja Tentang Reproduksi dengan Perilaku Seks Pranikah di Konveksi Desa Jabung Kec. Plupuh. [Versi Elektronik]. Jurnal Kebidanan, Vol. 2(2), 33.

Stang \& Mambaya, E. (2011). Faktor yang Berhubungan Dengan Pernikahan Dini Di Kelurahan Pangli Kecamatan Sesean Kabupaten Toraja Utara. [Versi Elektronik]. Jurnal MKMI, Vol. 7(1), 105-110.

Susanto, C.E. (2013). Angka Kehamilan Remaja Meningkat. Diakses pada 6 Februari 2015 dari metrotvnews.com/read/2013/angka-kehamilan-remaja-meningkat

Uecker, J. E. (2012). Marriage and Mental Health among Young Adults. [Versi Elektronik]. Journal of Health and Social Behavior, Vol. 53(1), 67-83. 